\title{
Gender Differences in the Management of Diabetic Patients with Hypertension and Chronic Ischemic Heart Disease
}

\author{
${ }^{I}$ Department of Cardiology, Hospital Ramón y Cajal, Madrid, Spain \\ ${ }^{2}$ Department of Cardiology, Hospital Infanta Sofia, Madrid, Spain \\ ${ }^{3}$ Primary care center Rosa Luxemburgo, Madrid, Spain \\ ${ }^{4}$ Department of Nephrology, Hospital Infanta Sofia, Madrid, Spain
}

Vivencio Barrios ${ }^{*}, 1$, Carlos Escobar ${ }^{2}$, Alberto Calderón ${ }^{3}$ and Rocio Echarri ${ }^{4}$

\begin{abstract}
Objective: To determine gender differences in cardiovascular risk factors control and clinical management in hypertensive diabetics with chronic ischemic heart disease. Research design and methods: CINHTIA was a cross-sectional and multicenter survey aimed to evaluate the clinical profile and management of hypertensive outpatients with chronic ischemic heart disease attended by cardiologists in Spanish clinical practice setting. The aim of the present work was to examine the gender differences in the control and treatment of cardiovascular risk factors in the subgroup of patients with diabetes. Adequate blood pressure (BP), LDL-cholesterol and diabetes control rates were defined according to ESH-ESC 2003, NCEP-ATP III and ADA-2005 guidelines, respectively.
\end{abstract}

Results: A total of 654 patients (42.4\% women) were included for the present analysis. Women were older. Smoking, sedentary lifestyle and peripheral arterial disease were more frequent in men; left ventricular hypertrophy and heart failure in women. The total number of lipid lowering and antihypertensive agents were similar between genders, but with a trend to use more antidiabetic drugs in women. There was a tendency to a better BP control in men $\left(21.5 \% v_{s} 17.0 \%, \mathrm{p}=0.09\right)$. LDL-cholesterol and diabetes were better controlled in men $(34.6 \% v s 26.6 \%, \mathrm{p}=0.04$ and $29.7 \% v s 22.3 \%$, $\mathrm{p}=0.025$, respectively).

Conclusions: Diabetic women with hypertension and chronic ischemic heart disease exhibit lower control rates of cardiovascular risk factors.

Keywords: Hypertension, cardiologist setting, chronic ischemic heart disease, men, women, diabetes, cardiovascular risk factors, control.

\section{INTRODUCTION}

Cardiovascular disease is the most important cause of death among women [1]. Despite that, it seems that many physicians and patients do not actually perceive the coronary risk in females [2]. This could be related with the fact that many physicians do not realize the magnitude of this epidemic in women, and could result in significant worse risk factors control rates [3].

Although in the last years there is a growing awareness about this matter, available information on gender differences is still scarce and mainly provided from US population $[4,5]$. Recently, it has been published a study with data from Germany [6]; but., it would be interesting to determine potential gender disparities in populations with a different risk profile, hypothetical lower, such as Mediterranean countries [7].

CINHTIA (Cardiopatía Isquémica cróNica e HiperTensIón Arterial en la práctica clínica en España) was a

\footnotetext{
*Address correspondence to this author at the Department of Cardiology, Hospital Ramón y Cajal, Ctra. De Colmenar km 9,100, 28034 Madrid, Spain; Tel: +34913368259; Fax: +34913368665;

E-mails: vbarriosa@meditex.es, vbarrios.hrc@salud.madrid.org
}

cross-sectional and multicenter survey aimed to evaluate the clinical profile and management of hypertensive outpatients with chronic ischemic heart disease attended by cardiologists in Spanish clinical practice setting. The main results of this survey have recently been published $[8,9]$. The aim of the present work was to examine the gender differences in the control and treatment of cardiovascular risk factors in the subgroup of patients with diabetes.

\section{RESEARCH DESIGN AND METHODS}

The methods and design of the study have been previously described $[8,9]$. Briefly, a total of 112 investigators, all of them cardiologists, participated in the study. Each investigator was asked to include consecutively patients' $\geq 18$ years, both genders, with an established diagnosis of hypertension and chronic ischemic heart disease. Patients with an acute coronary syndrome within the three previous months were excluded.

Chronic ischemic heart disease was defined as the presence of stable angina pectoris, evidence of myocardial ischemia assessed by stress tests, history of myocardial infarction for $>3$ months or previous revascularization (surgical or percutaneous). The presence of cardiovascular risk factors, organ damage or associated clinical conditions was 
Table 1. Clinical Characteristics of the Study Population $(n=654)$

\begin{tabular}{|c|c|c|c|}
\hline & Male $(n=377 ; 57.6 \%)$ & Female $(n=277 ; 42.4 \%)$ & $\mathbf{p}$ \\
\hline Age (years) & $67.0 \pm 9.6$ & $69.6 \pm 7.8$ & $<0.0001^{2}$ \\
\hline BMI $\left(\mathrm{kg} / \mathrm{m}^{2}\right)$ & $28.9 \pm 3.6$ & $29.4 \pm 4.5$ & $0.092^{2}$ \\
\hline Atrial fibrillation (\%) & 16.2 & 31.5 & $<0.0001^{1}$ \\
\hline LVEF $(\%)$ & $54.5 \pm 12.8$ & $56.3 \pm 11.7$ & $0.118^{1}$ \\
\hline \multicolumn{4}{|c|}{ Cardiovascular Risk Factors ${ }^{1}$} \\
\hline Dyslipidemia (\%) & 88.5 & 89.3 & 0.790 \\
\hline Current smoker $(\%)$ & 13.6 & 4.2 & $<0.0001$ \\
\hline Ex-smoker (>1 year quit smoking) $(\%)$ & 40.9 & 5.7 & $<0.0001$ \\
\hline Sedentary lifestyle (\%) & 71.9 & 55.4 & $<0.0001$ \\
\hline \multicolumn{4}{|c|}{ Organ Damage $^{1}$} \\
\hline Left ventricular hypertrophy (\%) & 49.9 & 62.4 & 0.001 \\
\hline Heart failure (\%) & 24.6 & 38.1 & $<0.0001$ \\
\hline Peripheral artery disease (\%) & 27.4 & 14.2 & $<0.0001$ \\
\hline Renal function insufficiency (\%) & 20.6 & 20.4 & 0.99 \\
\hline Stroke $(\%)$ & 10.2 & 10.8 & 0.89 \\
\hline \multicolumn{4}{|c|}{ Physical Examination $^{2}$} \\
\hline $\mathrm{SBP}(\mathrm{mmHg})$ & $143.6 \pm 17.6$ & $146.9 \pm 17.3$ & 0.018 \\
\hline $\mathrm{DBP}(\mathrm{mmHg})$ & $81.9 \pm 10.8$ & $84.5 \pm 12.3$ & 0.006 \\
\hline HR (bpm) & $68.5 \pm 11.0$ & $71.5 \pm 10.6$ & $<0.0001$ \\
\hline \multicolumn{4}{|c|}{ Biochemical Parameters $^{2}$} \\
\hline Total cholesterol (mg/dl) & $193.9 \pm 47.6$ & $208.5 \pm 46.4$ & $<0.0001$ \\
\hline Triglycerides (mg/dl) & $160.6 \pm 55.9$ & $160.2 \pm 58.4$ & 0.962 \\
\hline LDL-cholesterol (mg/dl) & $112.1 \pm 38.3$ & $120.4 \pm 36.7$ & 0.009 \\
\hline HDL-cholesterol (mg/dl) & $48.6 \pm 23.3$ & $49.2 \pm 17.1$ & 0.736 \\
\hline Serum fasting glucose (mg/dl) & $151.4 \pm 44.9$ & $157.9 \pm 44.1$ & 0.076 \\
\hline Creatinine $(\mathrm{mg} / \mathrm{dl})$ & $1.31 \pm 1.1$ & $1.35 \pm 1.1$ & 0.752 \\
\hline Uric acid $(\mathrm{mg} / \mathrm{dl})$ & $6.8 \pm 5.5$ & $6.6 \pm 5.8$ & 0.787 \\
\hline \multicolumn{4}{|c|}{ Treatment $^{1}$} \\
\hline$\geq 4$ drugs $(\%)$ & 96.7 & 97.0 & 0.666 \\
\hline Antihypertensive drugs ( $\geq 2$ agents) (\%) & 95.5 & 96.8 & 0.765 \\
\hline Beta blockers (\%) & 64.9 & 62.0 & 0.455 \\
\hline CCB $(\%)$ & 45.7 & 53.9 & 0.045 \\
\hline ACEIs (\%) & 44.8 & 40.2 & 0.258 \\
\hline Diuretics (\%) & 38.9 & 53.9 & $<0.001$ \\
\hline ARB (\%) & 38.0 & 44.3 & 0.122 \\
\hline Alpha blockers (\%) & 6.3 & 3.3 & 0.102 \\
\hline Lipid lowering drugs & 77.7 & 77.5 & 1.000 \\
\hline Statins & 75.0 & 73.1 & 0.585 \\
\hline Ezetimibe & 10.1 & 17.0 & 0.012 \\
\hline Fibrates & 4.9 & 5.2 & 1.000 \\
\hline Others & 0.8 & 2.2 & 0.179 \\
\hline Antidiabetics & 84.8 & 89.7 & 0.045 \\
\hline Oral antidiabetics & 68.2 & 64.9 & 0.396 \\
\hline Insulin & 21.7 & 33.2 & 0.01 \\
\hline Anticoagulants & 13.6 & 27.3 & $<0.001$ \\
\hline Antiplatelets & 91.6 & 77.1 & $<0.001$ \\
\hline
\end{tabular}




\begin{tabular}{|c|c|c|c|}
\hline & Male $(n=377 ; 57.6 \%)$ & Female $(n=277 ; 42.4 \%)$ & $\mathbf{p}$ \\
\hline \multicolumn{4}{|c|}{ Diagnostic Procedures $^{1}$} \\
\hline Electrocardiogram (\%) & 100 & 99.6 & 0.425 \\
\hline Echocardiogram (\%) & 85.0 & 83.1 & 0.580 \\
\hline Exercise test $(\%)$ & 57.2 & 44.1 & 0.001 \\
\hline Radio-isotopic exam (\%) & 23.2 & 31.7 & 0.025 \\
\hline Stress echocardiogram (\%) & 6.3 & 4.0 & 0.265 \\
\hline Cardiac catheterism $(\%)$ & 69.4 & 49.6 & $<0.00$ \\
\hline
\end{tabular}

BMI: body mass index; LVEF; left ventricular ejection fraction; SBP: systolic blood pressure; DBP: diastolic blood pressure; HR: heart rate; CCB: calcium channel blockers; ACEIs: angiotensin converting enzyme inhibitors; ARB: angiotensin II receptor blockers.

${ }^{1}$ Chi-square test.

${ }^{2}$ Student's t-test.

recorded from the patients' clinical history. All of them were defined according to the ESH-ESC 2003 guidelines [10]. Sedentary lifestyle was defined as the physical activity shorter than a 30 minute daily walk.

Since this study was performed in the second quarter of 2007, adequate blood pressure (BP), LDL-cholesterol and glycemic control rates were defined according to the current guidelines in 2007, what means the ESH-ESC 2003, NCEPATP III and ADA 2005 guidelines, respectively [10-12].

\section{RESULTS}

In the CINHTIA study a total of 2,024 hypertensive patients with chronic ischemic heart disease were included (31.7\% female). Overall 654 patients $(32.3 \%)$ were diabetics (377 men [57.6\%], 277 women [42.4\%]). Table 1 summarizes the clinical characteristics of the study population. Women were older and had an increased prevalence of atrial fibrillation. The presence of concomitant cardiovascular risk factors and organ damage was very common in both genders. Smoking, sedentary lifestyle and peripheral arterial disease were more frequent in men and left ventricular hypertrophy and heart failure rates were higher in women. Both systolic and diastolic BP, heart rate, total cholesterol, LDL- and HDL-cholesterol values were higher in women.

Concerning to treatment, almost all the patients were taking at least 4 drugs, and $\geq 2$ antihypertensive agents, without significant differences between genders in the total number of drugs. The overall number of lipid lowering drugs was also similar in both sexes, but there was a trend to prescribe more antidiabetics in women. However, males were taking more antiplatelets and females more anticoagulants, likely to be related with a higher prevalence of atrial fibrillation. Interestingly, calcium channel blockers, diuretics and insulin were more frequently used in women (Table 1).

Focusing on risk factors control rates, there was a tendency to a better BP control $\mathrm{n}$ men $(21.5 \%$ vs $17.0 \%$, $\mathrm{p}=0.09)$. LDL-cholesterol and diabetes control rates were both higher in males $(34.6 \%$ vs $26.6 \%, \mathrm{p}=0.04 ; 29.7 \%$ vs $22.3 \%, \mathrm{p}=0.025$, respectively).

Finally, the diagnostic methods performed in this population according to gender were examined. Exercise test and cardiac catheterization were more commonly performed in male gender, and radio-isotopic exams in women (Table 1).

\section{DISCUSSION}

In this Spanish survey, the results showed that despite a similar number of antihypertensive and lipid lowering drugs, a lesser proportion of women attained BP, LDL-cholesterol and diabetes control rates. This fact may be related with the circumstance that females had more organ damage, and in this situation is more difficult to achieve cardiovascular risk factors goals [13]. Previous studies have reported worse control rates in women, including BP, LDL-cholesterol and HbAlc values [4-6]; although some of them found that women with diabetes received less treatment for modifiable coronary heart disease risk factors than diabetic men $[5,6]$, others have reported this poorer control with a similar intensity of medication management [4].

Although women have a similar or slightly higher prevalence of angina pectoris [14], this survey showed that men were more likely to undergo stress tests and coronary angiography. As a result, hypertensive diabetic women with coronary heart disease appeared to be under-diagnosed and this might have clinically relevant implications.

It has been reported that a multiple intensive intervention treating the associated risk factors markedly improves cardiovascular prognosis in at-risk patients with type 2 diabetes [15]. All these data suggest that despite the clinical management of women with diabetes has improved, it is necessary to increase the awareness of physicians for this population. Since women often exhibit a worse clinical profile, it is likely that women need a more aggressive approach than men to achieve cardiovascular risk factors targets.

The cross-sectional design of the study was chosen to best represent the "real world" of the clinical practice. Consequently, a large population of hypertensive patients achieved by consecutive sampling was included in the trial. But this methodology has its limitations, since it reduces the level of control that can be exercised to reduce variation and bias. As our study was carried out in a population attended by cardiologists in Spain, the data could be generalized probably only to those countries with the same health care delivery and cardiovascular risk profile.

In conclusion, diabetic women with hypertension and chronic ischemic heart disease have lower control rates of cardiovascular risk factors than men despite a similar intensity of treatment. 


\section{ACKNOWLEDGEMENTS}

The authors wish to express their sincere gratitude to all investigators who have actively participated in this study. The present study was supported by an unrestricted grant provided by Recordati España S.L. All data have been recorded and analyzed independently to prevent bias.

The authors have no relevant conflict of interest to disclose.

\section{REFERENCES}

[1] Fox CS, Evans JC, Larson MG, Kannel WB, Levy D. Temporal trends in coronary heart disease mortality and sudden cardiac death from 1950 to 1999. The Framingham Heart Study. Circulation 2004; 110: 522-7.

[2] Mosca L, Linfante AH, Benjamin EJ, et al. National study of physician awareness and adherence to cardiovascular disease prevention guidelines in the United States. Circulation 2005; 111: 499510.

[3] Mosca L, Banka CL, Benjamin EJ, et al. Evidence-based guidelines for cardiovascular disease prevention in women: 2007 update. Circulation 2007; 115: 1481-501.

[4] Ferrara A, Mangione CM, Kim C, et al. Sex disparities in control and treatment of modifiable cardiovascular disease risk factors among patients with diabetes. Diabetes Care 2008; 31: 69-74.

[5] Wexler DJ, Grant RW, Meigs JB, Nathan DM, Cagliero E. Sex disparities in treatment of cardiac risk factors in patients with type 2 diabetes. Diabetes Care 2005; 28: 514-20.

[6] Gouni-Berthold I, Berthold HK, Mantzoros CS, Böhm M, Krone W. Sex disparities in the treatment and control of cardiovascular risk factors in type 2 diabetes. Diabetes Care 2008; 31:1389-91.
[7] Gil-Guillén V, Orozco-Beltrán D, Maiques-Galán A, et al. Agreement between REGICOR and SCORE scales in identifying high cardiovascular risk in the Spanish population. Rev Esp Cardiol 2007; 60:1042-50.

[8] Barrios V, Escobar C, Bertomeu V, Murga N, de Pablo C, Calderon A. Risk factor control in the hypertensive patients with chronic ischemic heart disease attended in cardiologic outpatient clinics. The CINHTIA study. Rev Clin Esp 2008; 208: 397-401.

[9] Barrios V, Escobar C, Bertomeu V, Murga N, de Pablo C, Calderon A. Sex differences in the hypertensive population with chronic ischemic heart disease. J Clin Hypertens (Greenwich) 2008; 10: 779-86.

[10] European Society of Hypertension-European Society of Cardiology Guidelines Committee. European Society of Hypertension - European Society of Cardiology guidelines for the management of arterial hypertension. J Hypertens 2003; 1011-53.

[11] National Cholesterol Education Program (NCEP) Expert Panel on Detection, Evaluation, and Treatment of High Blood Cholesterol in Adults (Adult Treatment Panel III). Third Report of the National Cholesterol Education Program (NCEP) Expert Panel on Detection, Evaluation, and Treatment of High Blood Cholesterol in Adults (Adult Treatment Panel III) final report. Circulation 2002; 106: 3143-21.

[12] American Diabetes Association. Clinical practice recommendation. Diabetes Care 2005; 28(Suppl 1): S1-79.

[13] Barrios V, Escobar C, Echarri R, Matalí A. Gender and blood pressure control. Hypertension 2008; 51: e48.

[14] Hemingway H, Langenberg C, Damant J, Frost C, Pyörälä K, Barrett-Connor E. Prevalence of angina in women $v s$ men: a systematic review and meta-analysis of international variations across 31 countries. Circulation 2008; 117: 1526-36.

[15] Gaede P, Vedel P, Larsen N, Jensen GV, Parving HH, Pedersen O. Multifactorial intervention and cardiovascular disease in patients with type 2 diabetes. N Eng1 J Med 2008; 358: 580-91. 